\title{
Risk factors associated with failures of Varroa treatments in honey bee colonies without broodless period
}

\author{
Agostina Giacobino ${ }^{1}$, Ana Molineri ${ }^{3}$, Natalia Bulacio CAGNolo ${ }^{2}$, Julieta Merke ${ }^{2}$, \\ Emanuel Orellano ${ }^{2}$, Ezequiel BertozZI ${ }^{2}$, Germán MASCIÁNGELO ${ }^{2}$, \\ Hernán Pietronave ${ }^{2}$, Adriana PacinI ${ }^{1}$, César Salto ${ }^{2}$, Marcelo SignorinI ${ }^{1}$ \\ ${ }^{1}$ Consejo Nacional de Investigaciones Científicas y Técnicas, Instituto Nacional de Tecnología Agropecuaria EEA \\ Rafaela, Ruta 34 Km 227, Rafaela C.P. 2300 Provincia de Santa Fe, Argentina \\ ${ }^{2}$ Instituto Nacional de Tecnología Agropecuaria EEA Rafaela, Ruta 34 Km 227, Rafaela C.P. 2300 Provincia de Santa Fe, \\ Argentina \\ ${ }^{3}$ Facultad de Ciencias Veterinarias, UNL, Kreder 2805, Esperanza C.P. 3080 Provincia de Santa Fe, Argentina
}

Received 13 June 2014 - Revised 9 December 2014 - Accepted 30 December 2014

\begin{abstract}
The treatment against Varroa destructor has become a basic tool in beekeeping practices, mainly during autumn. The treatment effectiveness should be improved by identifying variables affecting the final outcome. The aim of this study was to identify the risk factors associated with the treatment outcome achieved during autumn control of Varroa destructor. The mite infestation after treatment was evaluated in 62 apiaries and data regarding management practices were collected by means of a questionnaire. A mixed-effects model was constructed to associate management variables with the risk of treatment failure occurrence. Colonies with high mite levels prior to treatment $(P=0.002)$ and owned by beekeepers who did not frequently replace queens $(P=0.001)$ were associated with a higher risk of treatment failure. Other beekeeping practices indirectly improved treatment effectiveness. An integrated strategy for controlling mites that includes chemotherapy and suitable beekeepers management is needed to keep mite populations low during winter.
\end{abstract}

\section{Varroa destructor / Apis mellifera / chemical acaricides / treatment effectiveness / management practices}

\section{INTRODUCTION}

Worldwide apiculture is threatened by the ectoparasitic mite Varroa destructor (Anderson and Trueman), since its host range has been successfully extended all around the world (Oldroyd 1999; Rosenkranz et al. 2010). The treatment against Varroa mites has become a basic tool in beekeeping practices (Genersch 2010) mainly to keep the autumn infestation rate under the threshold indicated for an acceptable colony loss rate during winter (Genersch et al. 2010). There are few strategies to keep $V$. destructor populations

Corresponding author: A. Giacobino, agostinagiacobino@hotmail.com

Manuscript editor: Peter Rosenkranz below injurious levels in honey bee colonies (Rosenkranz et al. 2010), being chemical substances widely used. Both the easy application and the economic convenience are still preferred advantages and therefore, many beekeepers decided to use at least one chemical treatment a year (Lodesani et al. 2006). However, there are some limitations such as the parasite resistance (Milani 1999; Elzen et al. 2000; Goodwin et al. 2005; Maggi et al. 2011) and the variability of efficacy (Underwood and Currie 2003; Aldea et al. 2012; Dietemann et al. 2012).

A wide diversity of integrated pest management tactics have been proposed and tested for $V$. destructor population control (Imdorf et al. 2003; Calderone 2005; Delaplane et al. 2005; Currie and Gatien 2006). While abandoning of 
chemical control seems hard to achieve, the frequency of synthetic acaricides application must be partially reduced and its efficacy should be maximized. For instance, seasonal differences (Currie and Gatien 2006), treating according to label instructions, the active ingredient rotation (Rosenkranz et al. 2010), and the sanitary condition of honey bee colonies are some of the driving variables that might affect the treatment final outcome. Likewise, $V$. destructor control effectiveness in temperate climates might depend on brood availability in the colonies. The simulation of the Varroa population dynamics predicted fewer mites for a short season condition with a defined break in brood rearing during winter than for a long season of brood availability (Vetharaniam 2012).

Additionally, a spatial analysis approach is required in order to identify zones tending to concentrate control failure either due to beekeeping practices variation or environmental factors. The aim of this study was to identify the risk factors associated with the treatment outcome achieved during autumn control of $V$. destructor.

\section{MATERIALS AND METHODS}

\subsection{Study design and sample size}

A cross sectional study was carried out from April to June 2013, in east-central Argentina (Santa Fe province). The sampling time was at the end of the acaricide treatment period (45 days after treatment began) to check mite levels of the colonies before winter season. Since the sampling time varied according to treatment initiation date, a time frame of approximately 3 months was defined between the first and last sampling date.

Apiaries were randomly chosen following stratified randomization procedures (computerized random numbers) (Moher et al. 2010). A total of 62 apiaries ( $n=3735$; $95 \%$ confidence level; precision $=10.5 \%$ ) were sampled during the late autumn season, being consistent with the number of apiaries in Santa $\mathrm{Fe}$ province. Within each apiary, a minimum of six colonies or $10 \%$ of the total colonies (Lee et al. 2010) have been randomly selected to evaluate $V$. destructor infestation level after acaricide treatment. As a result, a total number of 377 colonies were analyzed.

\subsection{Data collection}

A sample of approximately 300 adult worker bees per colony was collected from both sides of three unsealed brood combs and placed in a jar filled with alcohol. Adult bees were examined using the warm/ soap water method to diagnose the presence of phoretic mites in bee colonies and to estimate the infestation rate of adult bees (Dietemann et al. 2013). In addition, the populations of adult bees and brood, as well as pollen and honey reserves were measured in colonies by estimating the total area of comb covered by adult bees, brood, sealed honey, and pollen (DeGrandi Hoffman et al. 2008; vanEngelsdorp et al. 2009). Once each hive was opened, each frame was sequentially removed and the percentage of coverage on both sides was estimated.

A monitoring questionnaire was answered by the participating beekeepers in order to gather information about: general apiary traits (i.e., geographic location, number of colonies, average honey production, and winter mortality per year), commonly performed management practices (carbohydrates and protein diets, monitoring of mite levels in the colonies measured by the beekeepers, queen replacement, making nuclei, colonies migration), and acaricide treatment against Varroa mites (active ingredient, date of treatment, chemical rotation during the last 4 years). Additional information concerning apiary management practices could be obtained from the complete questionnaire (available as supplemental material in Giacobino et al. 2014).

The prevalence of colonies with more than $1 \%$ of $V$. destructor infestation after an autumn acaricide treatment was estimated from diagnose examination of 377 honey bee colonies. The colonies with $>1 \%$ of Varroa infestation after control treatment were considered as treatment failure (TF) colonies. This threshold was set, assuming that colonies that undergo winter with available brood should keep Varroa phoretic levels as low as possible, since $85-90 \%$ of Varroa are in cells during a brood cycle (Vetharaniam 2012). This is rather important for colonies from a temperate climate without broodless period given that the proportion of total mites within capped brood is a significant linear predictor of the growth rate (Harris et al. 2003). The focus of our analysis was set in the final levels of Varroa of the overwintering colonies according to the management decisions including acaricide treatment. 


\subsection{Statistical analysis}

All potential predictor variables and the prevalence of TF colonies $(>1 \%)$ were examined using the Pearson chi square test of independence $\left(\chi^{2}\right)$. All variables with a significance value of $P<0.15$ were selected. The collinearity between the selected variables was performed by a Pearson's chi square test. When two potential risk factors were associated, only one was offered to the multivariable analysis.

A mixed-effect logistic regression with apiary as the random effect was adjusted for the significant factors previously tested. Variables with a $P<0.05$, calculated using the Wald test, were maintained in the model. All the statistical analyses were carried out using the InfoStat software (Universidad Nacional de Córdoba, Argentina).

\subsection{Spatial analysis}

The spatial scan statistic method for cluster detection (Kulldorff and Nagarwalla 1995) was used to identify and test the significance of specific clusters for a heterogeneous population distribution. The data set was scanned for windows with less and more cases of TF colonies (low and high rates, respectively) than expected, equivalent to a two-sided statistical test. A likelihood ratio test statistic was calculated for each window and the scanning upper limit was set at $50 \%$ of the population at risk. The distribution of TF colonies was assumed to be Bernoulli (for instance cases $>1 \%$ and non-cases $\leq 1 \%$ ), the most likely cluster along with secondary clusters were reported (Kulldorff 2014). All analyses were performed using SaTScan software version 9.2 (www.satscan.org).

\section{RESULTS}

A total of $76(20.2 \%)$ out of 377 colonies showed an infestation higher than $1 \%$ (1 mite per 100 bees) after treatment against $V$. destructor and were considered as TF colonies. The mean abundance of $V$. destructor (per colony) before treatment was $0.05 \pm 0.06$ mites per adult bee ( 5 mites per 100 bees). Before treatment, combs covered by adult bees per colony were 8.70 \pm 1.39 and combs covered by brood were 4.63 \pm 1.87 . The number of combs covered by brood at the beginning of the treatment was similar
$(P=0.192)$ between TF colonies $(4.43 \pm 1.44)$ and colonies $<1 \%$ after treatment $(4.7 \pm 1.96)$. The average sealed honey and pollen stored were $2.97 \pm 1.62$ and $0.86 \pm 0.66$ combs, respectively. At the end of treatment, colonies had $7.32 \pm 1.78$ combs covered by adult bees, $1.46 \pm 1.18$ combs covered by brood, $3.56 \pm 1.80$ combs of sealed honey, and $0.58 \pm 0.69$ combs of stored pollen. The most used acaricide during Autumn 2013 was flumethrin strips (43 out of 62 beekeepers), followed by amitraz (10 beekeepers), oxalic acid ( 5 beekeepers), and coumaphos (4 beekeepers). Most of the beekeepers (90.5\%) applied a commercial acaricide: $69.8 \%$ used Flumevar ${ }^{\circledR}$ (Flumethrin strip $0.34 \mathrm{~g} / 100 \mathrm{~g}$ of product), $14.3 \%$ used Amivar ${ }^{\circledR}$ (Amitraz $4.13 \mathrm{~g} / 100 \mathrm{~g}$ of product), $3.2 \%$ Cumavar $^{\circledR}$ (Coumaphos strips $8.5 \mathrm{~g} / 100 \mathrm{~g}$ of product) and $3.2 \%$ Oxavar $^{\circledR}$ (powder of Oxalic acid $97 \mathrm{~g} / 100 \mathrm{~g}$ of product). Homemade formulations were uncommon $(9.5 \%)$.

After the univariable analysis, 14 out of the total potential explanatory variables tested were selected (selected variables had a significance value of $P<0.15$ ) to be included in the mixed-effects logistic regression model. Elected variables after collinearity test $(P<0.05)$ were as follows: the percentage of Varroa infestation prior to treatment, carbohydrate and protein diet, autumn acaricide product, date of treatment and active ingredient rotation, spring treatment management, monitoring Varroa levels, apiary location, apicultural experience, queen replacement, making nuclei, colony migration, and percentage of comb replacement (Table I).

The final multivariate model identified two variables associated with the prevalence of TF colonies (Table I). The apiary random effect was significant $(P<0.01)$. The probability of TF colonies increased when queen replacement was not performed (odds ratio $(\mathrm{OR})=8.849 ; 95 \%$ confidence interval $(\mathrm{CI})=2.551-30.303 ; P=0.001)$, as well as when the percentage of infestation prior to treatment was $3 \%$ or more $(\mathrm{OR}=4.884 ; 95 \%$ $\mathrm{CI}=1.820-13.102 ; P=0.002)$ (Table I). Additionally, we found that variables removed from the multivariate model were associated either with queen replacement or with the percentage of Varroa prior to treatment (Figure 1). Spring treatment $(P=0.007)$, active ingredient rotation 
Table I. Final mixed-effects logistic regression model for apiary factors associated with $V$. destructor high prevalence $(>1 \%)$ in honey bee colonies after autumn acaricide treatment (random effect: apiary; $n=341$ ).

\begin{tabular}{|c|c|c|c|c|}
\hline Variable & Level & Odds ratio & 95 \% CI (OR) & $P$ value ${ }^{\mathrm{b}}$ \\
\hline Intercept & & $34.833 \pm 323.577^{\mathrm{a}}$ & & 0.914 \\
\hline \multirow[t]{2}{*}{ Protein diet } & No (ref.) & - & - & - \\
\hline & Yes & - & - & 0.639 \\
\hline \multirow[t]{2}{*}{ Carbohydrate supply } & No-sucrose (ref.) & - & - & - \\
\hline & HFCS & - & - & 0.924 \\
\hline \multirow[t]{2}{*}{ Queen replacement } & Yes (ref.) & - & - & - \\
\hline & No & 8.849 & $2.551-30.303$ & $0.001 *$ \\
\hline \multirow[t]{2}{*}{$\%$ of Varroa prior to treatment } & Less than $3 \%$ (ref.) & - & - & - \\
\hline & $3 \%$ or more than $3 \%$ & 4.884 & $1.820-13.102$ & $0.002 *$ \\
\hline \multirow[t]{2}{*}{ Monitoring before treatment } & Yes (ref.) & - & - & - \\
\hline & No & - & - & 0.591 \\
\hline \multirow[t]{4}{*}{ Zone } & Coast (ref.) & - & - & - \\
\hline & North & - & - & 0.995 \\
\hline & Center & - & - & 0.971 \\
\hline & South & - & - & 0.971 \\
\hline \multirow[t]{2}{*}{ Apicultural experience } & Less than 10 years (ref.) & - & - & - \\
\hline & 10 or more than 10 years & - & - & 0.147 \\
\hline \multirow[t]{2}{*}{$\%$ of nuclei per apiary } & Less than $50 \%$ (ref.) & - & - & - \\
\hline & $50 \%$ or more than $50 \%$ & - & - & 0.944 \\
\hline \multirow{2}{*}{$\begin{array}{l}\% \text { of annual comb replacement } \\
\text { per hive }\end{array}$} & 3 or less than 3 combs (ref.) & - & - & - \\
\hline & More than 3 combs & - & - & 0.941 \\
\hline \multirow[t]{2}{*}{ Colonies migration } & No & - & - & - \\
\hline & Yes & - & - & 0.922 \\
\hline \multirow[t]{2}{*}{ Acaricide rotation (last 2 years) } & No (ref.) & - & - & - \\
\hline & Yes & - & - & 0.979 \\
\hline \multirow[t]{2}{*}{ Spring acaricide treatment } & No (ref.) & - & - & - \\
\hline & Yes & - & - & 0.983 \\
\hline \multirow[t]{3}{*}{ Autumn treatment acaricide } & Organics & - & - & - \\
\hline & Flumethrin/amitraz & - & - & 0.972 \\
\hline & Coumaphos & - & - & 0.999 \\
\hline \multirow[t]{2}{*}{ Autumn treatment date } & Early (ref.) & - & - & - \\
\hline & Late & - & - & 0.903 \\
\hline
\end{tabular}

Ref reference category, $C I$ confidence interval, HFCS high fructose corn syrup

${ }^{\mathrm{a}} \mathrm{Beta} \pm \mathrm{SE}$

${ }^{\mathrm{b}}$ Significance of likelihood ratio test statistic; Apiary $(P>0.01)$

$(P=0.002)$, making nuclei $(P<0.0001)$, colony migration $(P<0.0001)$, comb replacement $(P=0.007)$, and protein diet $(P<0.0001)$ were associated with queen replacement. On the other hand, autumn treatment date $(P=0.001)$ was associated with the percentage of Varroa prior to treatment. In addition, monitoring before treatment $(P=0.001$ and $P=0.03)$, zone $(P=0.001$ and $P=0.017)$, carbohydrate supply $(P<0.0001$ and $P=0.008)$ and autumn treatment product $(P<0.0001$ and 


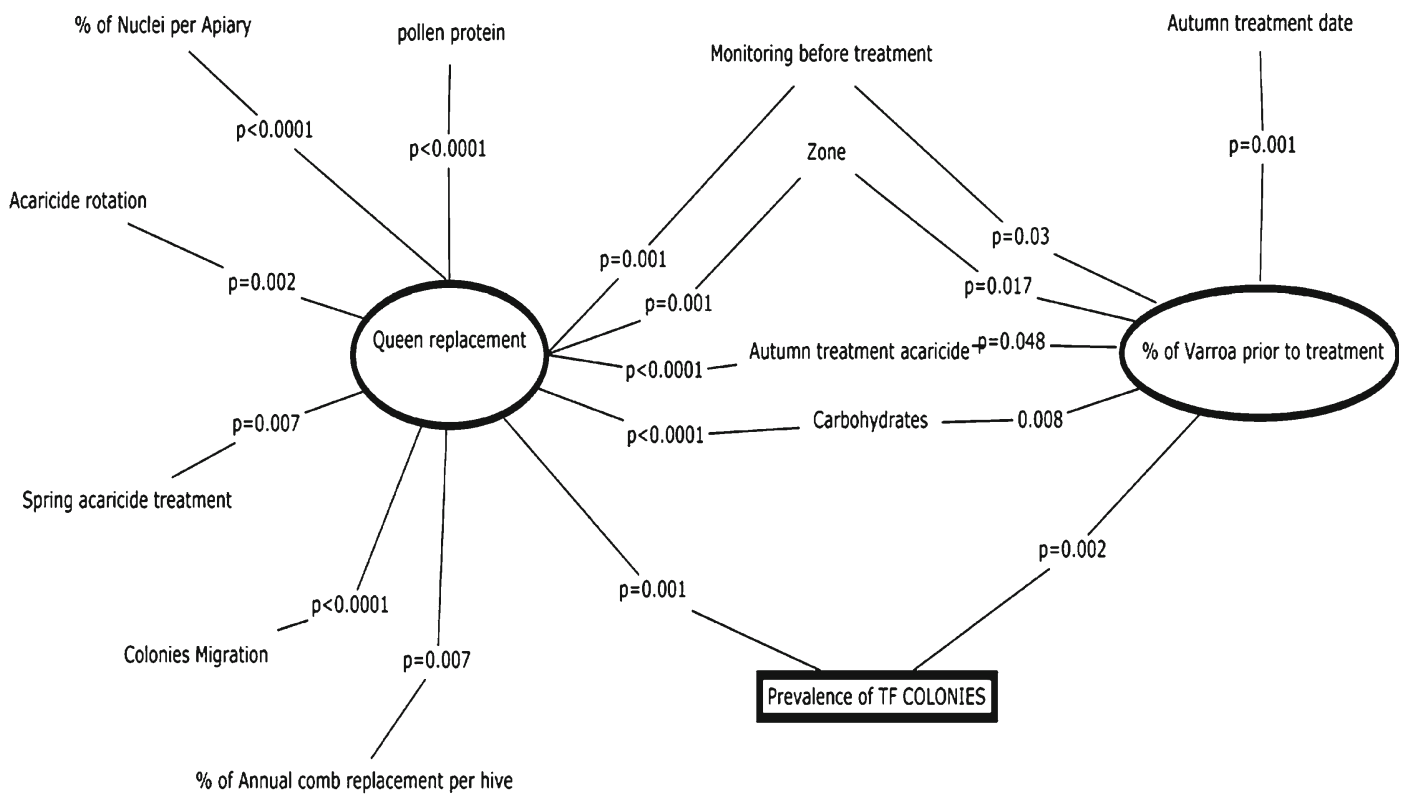

Figure 1. Association network between the significant explanatory variables in the univariate analysis $(P<0.15)$ and risk factors for TF colonies occurrence identified by the logistic regression mixed model outcome.

$P=0.048)$ were associated with risk factors, queen replacement, and Varroa previous level, respectively. The apicultural experience was not associated neither to queen replacement $(P=0.99)$ nor Varroa previous level $(P=0.6)$.

Two significant clusters were detected across the geographical range (Table II). The most likely cluster (ID number=1) had almost $115 \mathrm{~km}$ of radius and was the more extensive. It was located in the south of Santa Fe province (Figure 2a) and had a relative risk of 3.78 (high rate cluster). Any colony that was inside this cluster had almost four times higher possibilities to be a TF colony than the others outside the same cluster. The fact of it being inside a cluster was associated with some of the risk factors identified by the logistic model (Figure $2 \mathrm{a}$ ). A total of $60.5 \%$ of the colonies with $>3 \%$ of Varroa infestation before treatment were significantly associated with being in a high-rate cluster after treatment $(P=0.01)$ (Figure $2 b)$. In contrast, requeening in the colonies was not statistically associated with being in a high- or lowrate cluster $(P=0.626)$ (Figure $2 \mathrm{c}$ ).

In addition, all the colonies within a low-rate cluster received legal synthetic acaricide
$(P<0.0001)$ at an early date $(P<0.0001)$ and came from apiaries that usually rotate the chemical treatments $(P<0.0001)$. However, $71.4 \%$ of the colonies from a high rate cluster were also treated with legal synthetic acaricide.

\section{DISCUSSION}

There are several cases where the acaricide treatment failed, mainly as a consequence of resistance development (Lodesani et al. 1995, 2006; Goodwin et al. 2005). The misapplication of commercial products and homemade acaricides (Higes et al. 2010) enhances drug-resistant mite populations. The resistance also favors the escalation of chemical applications and increases residues of miticides in bee products (Tremolada et al. 2004; Bogdanov 2006; Le Conte et al. 2010). Furthermore, sub-lethal pesticide exposure can increase susceptibility to pathogen attack in colonies affected with colony collapse disorder (vanEngelsdorp et al. 2010). Within this context, adjusting some beekeeping practices associated with the improvement of the treatment concept may help to avoid the resistance development 
Table II. Summary of TF colonies spatial distribution variables (cluster detection), for low- and high-rate clusters ( $n=62$; total population $=379$; total number of TF colonies $=76$; maximum spatial cluster size $=50 \%$ of population at risk; number of replications $=999$ ).

\begin{tabular}{lccccc}
\hline \multicolumn{1}{c}{ Cluster } & ID & Cluster radius $(\mathrm{km})$ & Number of colonies & Relative risk & $P$ value \\
\hline Most likely & 1 & 114.46 & 123 & 3.78 & $<0.0001$ \\
Secondary & 2 & 39.59 & 64 & 0 & $<0.0001$ \\
\hline
\end{tabular}

Relative risk: $<1$ low rate of $\mathrm{TF}$ colonies; $>1$ high rate of $\mathrm{TF}$ colonies

problem of the compounds (Lodesani et al. 2006). Moreover, since flumethrin was the most frequently used product during 2013 and so far no resistance detection was reported for it in Argentina, treatment failure seems to be a multi-causal phenomenon.

The methodology for Varroa infestation assessment in the colonies is widely discussed (Dietemann et al. 2013). A number of available methods for the Varroa infestation assessment (using acaricides, monitoring natural mite fall, and assessing infestation levels) were found to provide comparable results (Branco et al. 2006). The selection of an appropriate method depends on several factors like the amount and situation of sampled colonies, the desired precision in the estimation consistent with the objective of the study, and an achievable sampling effort. Considering these study conditions (particularly, the distances from apiaries to the laboratory and the number of samples to analyze) the adult infestation rate per colony was estimated according to the sampling plan for researchers proposed by Lee et al. (2010).

As our results suggested, TF colonies had 4.9 times more risk of occurrence when the percentage of Varroa infestation prior to treatment was more than $3 \%$. Nevertheless, it is difficult to avoid high levels of mite populations since treatment can only be carried out after the harvest,
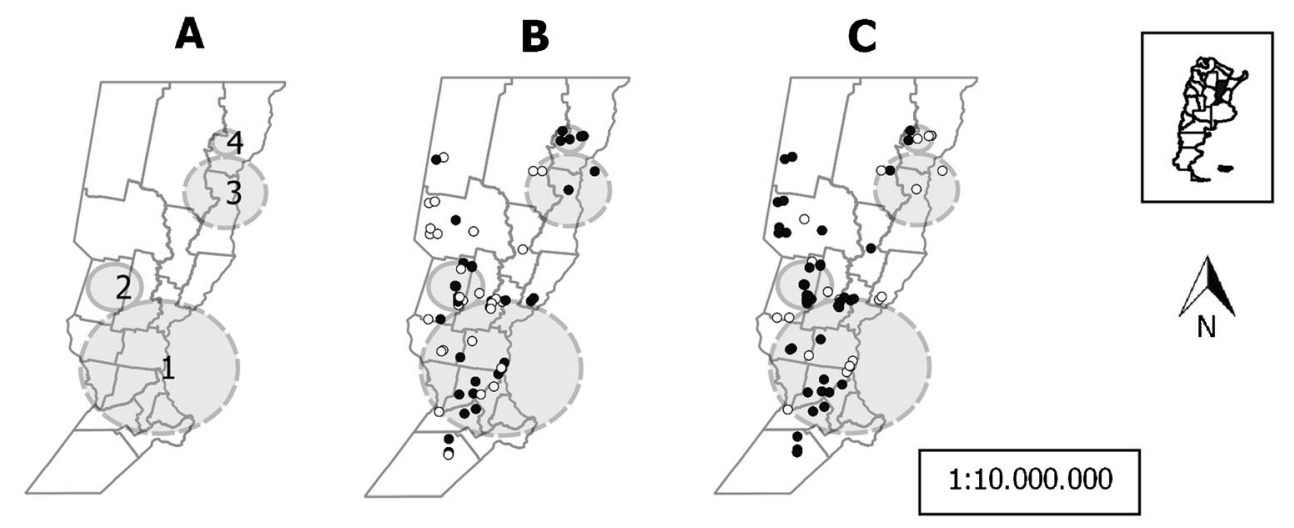

Figure 2. Monitored apiaries distribution from Santa Fe province $(n=62)$. a Cluster distribution (purely spatial) of percentage of Varroa destructor infestation after acaricide treatment; high rate (1 and 3) and low rate of TF colonies (2 and 4). b Spatial association between cluster distribution of TF Colonies and percentage of infestation with $V$. destructor prior to autumn acaricide treatment (black circle $>3 \%$ of infestation per colony; white circle $\leq 3 \%$ of infestation per colony). c Spatial association between cluster distribution of TF colonies and requeening (black circle yes; white circle no). 
when the mite population has often risen to injurious levels (Le Conte et al. 2010). However, management practices that help keeping lower Varroa infestation level are available, such as protein and carbohydrate diet, monitoring the colonies, and woodenware disinfection (Giacobino et al. 2014). Possibly, integrated strategies such as healthy and well-nourished bees along with mite level check-ups (monitoring) and the organic acaricide application during spring (Giovanezzo and Dubreuil 2011), if required, are key to enhance the treatment concept as a whole and avoid achieving an increased infestation level during autumn. This is important since autumn Varroa mite infestation is one of the potential causes of winter mortality in honey bee colonies (Genersch et al. 2010; Guzmán-Novoa et al. 2010; Le Conte et al. 2010).

Queen replacement had also a significant effect as a potential risk factor associated with the TF colonies occurrence. Requeening is a key feature associated with honey bee health as previous studies had suggested (Tarpy et al. 2000; Invernizzi et al. 2006; Schneider and DeGrandi Hoffman 2008; Botías et al. 2012). Furthermore, in apiaries where no queen replacement was performed, the risk of achieving an increased percentage of Varroa was higher (Giacobino et al. 2014). The health and fitness of a honey bee colony depends significantly on the quality of the queen (Botías et al. 2012), as the variation in her reproductive potential affects the entire colony organization (Tarpy et al. 2000). Also, the damage caused by a high Varroa mite infestation (Akyol et al. 2007) and infections rates of Nosema sp. (Botías et al. 2012) could be decreased in colonies that have young queens. As requeening is recommended to improve the hygienic behavior, a possible interaction with the acaricide treatment could decrease the probability of the TF colonies occurrence.

Some management practices are associated with risk factors of the TF colonies occurrence, since they improve the effectiveness of the treatment concept as a whole. This is likely because, generally, beekeepers that adhere to a management program keep the Varroa levels tolerable during autumn (Giacobino et al. 2014) and after treatment. The feeding with carbohydrate in the colonies might be related to the autumn mite level since better nourished bees improve their response to nutritional stresses accumulated in managed colonies (Mattila and Otis 2006). In addition, the treatment applied during early autumn helped to avoid the TF colonies occurrence (only $10 \%$ of TF colonies; $P<0.0001$ ), since the date of treatment had significant effects on colony mortality rates, mite levels, and brood area the following spring (Strange and Sheppard 2001).

Although the mean abundance of $V$. destructor prior to the application of acaricides in this study was lower than expected for autumn season in previous reports (Liebig 2001; Fries et al. 2003; Currie and Gatien 2006; Rosenkranz et al. 2010), the percentage of Varroa infestation prior to treatment seems to be highly associated with the probability of the TF colonies occurrence. Likewise, the $1 \%$ criterium set up for TF colonies in our study was below the threshold for economic damage related to winter colony losses in Germany (Genersch et al. 2010). Perhaps, the main difference was given by the fact that "autumn colonies" in Germany have already produced their winter bee population and usually they have little or no brood (Genersch et al. 2010). The ratio live/dead mites will change between periods when bee brood is present or absent (Martin 1998). Northern European countries have a shorter summer, resulting in a shorter brood period and fewer mite reproduction cycles, leading to a less Varroa -related risk of loss (van der Zee et al. 2014). Furthermore, practically all mites are phoretic during the winter months, which makes them vulnerable to control products. On the other hand, if colonies are not treated during late summer, when the host population declines, the relative Varroa infestation increases and consequently the production of healthy long-living winter bees is negatively impacted (Genersch et al. 2010). In contrast, the Argentinean situation is quite different mainly because, regardless of the temperate climate, in most regions, there is no broodless period (Marcangeli et al. 1992). The long season is also a typical condition of New Zealand, in which brood rearing often continues throughout winter (Vetharaniam 2012). The length of time over which brood cells are available exerts the greatest effect on mite population growth, thus Varroa infestation will be more severe in long brood- 
rearing seasons than in short ones (Wilkinson and Smith 2002).

Spatial cluster methods are the most common tools for assessing nonrandom spatial patterns (Auchincloss et al. 2012). The estimated practical range for $V$. destructor spread in New Zealand was $19 \mathrm{~km}$ (Stevenson et al. 2005), therefore, local clustering methods that test specific smallscale clusters, like spatial scan statistic, are suitable.

The spatial distribution of TF colonies was associated with the percentage of Varroa prior to treatment, independently of the acaricide treatment. The chemical treatment per se is not enough to guarantee that Varroa levels were reduced before winter. Therefore, both preventing the occurrence of high levels of Varroa during late summer and checking mite levels after the autumn treatment are key tools to maintain a healthy overwintering bee population. On the other hand, colonies from the low-rate cluster were associated with some recommended management practices like an early chemical treatment along with an active ingredient rotation. This supports the idea that the influence of the geographical zone on TF colonies is better explained by a coordinated response strategy, as discussed previously, than by a direct climate effect. Differently, high- or low-rate clusters were not associated with requeening though we found that it was a risk factor for the TF colonies occurrence. Possibly, a spatial aggregation of beekeepers that decide to perform queen replacement in their colonies is not present. As our results show, inside the high-rate cluster as well as inside the low-rate cluster, requeening and not requeening apiaries are present. Perhaps, circumstances where queen replacement may be restrained by personal economic factors arise and therefore it is not possible to find a spatial pattern.

Environmental factors may act indirectly on Varroa populations (Rosenkranz et al. 2010). The influence of the geographical zone on risk factors, such as queen replacement and the percentage of Varroa prior to treatment, might either indicate a direct effect of climate on mite fertility (Moretto et al. 1991; Harris et al. 2003) or a coordinated and regionalized response from beekeepers concerning mites control measures. Regardless, the geographical zone is a multifactorial variable that demands a constant and a thoughtful research effort beyond these study results.

\section{CONCLUSIONS}

The percentage of $V$. destructor infestation prior to treatment and queen replacement are factors associated with the treatment failure occurrence in mite control during autumn. Appropriate management practices are basic to improve the effectiveness of the treatment concept and therefore to keep mite populations low during winter. While synthetic acaricides are still the foremost choice in commercial beekeeping, strategies for the efficient and suitable management of the chemical control in the honey bee colonies are essential. Management practices that mainly help to avoid treatment failure before winter are highly valuable to be included in worldwide apiculture, especially in temperate climate without broodless period.

\section{ACKNOWLEDGMENTS}

This study has been carried out with the financial support of the PNAPI Specific Project No. 1112042 "Estrategias multidisciplinarias para mitigar el efecto del nuevo contexto ambiental y productivo sobre la colmena", Instituto Nacional de Tecnología Agropecuaria. Agostina Giacobino and Adriana Pacini are doctoral fellows from the Consejo Nacional de Investigaciones Científicas y Técnicas (CONICET, Argentina). Marcelo L. Signorini is a Research Career Member from the Consejo Nacional de Investigaciones Científicas y Técnicas (CONICET, Argentina).

Facteurs de risque associés à des échecs de traitement contre le Varroa dans des colonies d'abeilles $n$ 'ayant pas de périodes sans couvain

Varroa destructor / Apis mellifera / acaricides chimiques / efficacité du traitement / mode de conduite des ruches

Risikofaktoren in Verbindung mit einer unzureichenden Wirksamkeit bei der Varroa bekämpfung von Bienenvölkern ohne brutfreie Phasen

Varroa destructor / Apis mellifera / Akarizide / Bekämpfungserfolg / imkerliches Management 


\section{REFERENCES}

Akyol, E., Yeninar, H., Karatepe, M., Karatepe, B., Ozkok, D. (2007) Effects of queen ages on Varroa (Varroa destructor) infestation level in honey bee (Apis mellifera caucasica) colonies and colony performance. Ital. J. Anim. Sci. 6, 143-149

Aldea, P.-, Olivares, A., Rodríguez, R. (2012) Efficacy evaluation of organic treatments against Varroa mite in different climatic zones of Chile. 5th European Conference of Apidology (p. 217), 3-7th September 2012. Halle an der Saale, Germany.

Auchincloss, A.H., Gebreab, S.Y., Mair, C., Diez Roux, A.V. (2012) Review of Spatial Methods in Epidemiology, 2000-2010. Annu. Rev Public Health 33, 107-22

Bogdanov, S. (2006) Contaminants of bee products. Apidologie 37, 1-18

Botías, C., Martín-Hernández, R., Días, J., García-Palencia, P., Matabuena, M., Juarranz, A., Barrios, L., Meana, A., Nanetti, A., Higes, M. (2012) The effect of induced queen replacement on Nosema spp. infection in honey bee (Apis mellifera iberiensis) colonies. Environ Microbiol 14(4), 845-859

Branco, M.R., Kidd, N.A.C., Pickard, R.S. (2006) A comparative evaluation of sampling methods for Varroa destructor (Acari: Varroidae) population estimation. Apidologie 37, 452-461

Calderone, N.W. (2005) Evaluation of drone brood removal for management of Varroa destructor (Acari: Varroidae) in colonies of Apis mellifera (Hymenoptera: Apidae) in the northeastern United States. J. Econ Entomol. 98 (3), 645-50

Currie, R.W., Gatien, P. (2006) Timing acaricide treatments to prevent Varroa destructor (Acari: Varroidae) from causing economic damage to honey bee colonies. Can. Entomol. 138, 238-252

De Grandi Hoffman, G., Wardell, G., Ahumada Segura, F., Rinderer, T., Danka, R., Pettis, J. (2008) Comparisons of pollen substitute diets for honey bees: consumption rates by colonies and effects on brood and adult populations. J. Apic. Res. 47 (4), 265-270

Delaplane, K., Berry, J., Skinner, J., Parkman, J., Hood, W.M. (2005) Integrated pest management against Varroa destructor reduces colony mite levels and delays treatment threshold. J. Apic. Res. 44 (4), 157-162

Dietemann, V., Pflugfelder, J., Anderson, D., Charrière, J.D., Chejanovsky, N., et al. (2012) Varroa destructor: research avenues towards sustainable control. J. Apic. Res. 51 (1), 125-132

Dietemann, V., Nazzi, F., Martin, S. J., Anderson, D. L., Locke, B., et al. (2013) Standard methods for Varroa research. In Dietemann, V., Ellis, J. D., Neumann, P., (Eds) The COLOSS BEEBOOK, Volume II: standard methods for Apis mellifera pest and pathogen research. J. Apic. Res. 52 (1), DOI: 10.3896/IBRA.1.52.1.09

Elzen, P.J., Baxter, J.R., Spivak, M., Wilson, W.T. (2000) Control of Varroa jacobsoni Oud. resistant to fluvalinate and amitraz using coumaphos. Apidologie 31, 437-441

Fries, I., Hansen, H., Imdorf, A., Rosenkranz, P. (2003) Swarming in honey bees (Apis mellifera) and Varroa destructor population development in Sweden. Apidologie 34, 389-397

Genersch, E. (2010) Honey bee pathology: current threats to honey bees and beekeeping. Appl Microbiol. Biotechnol. 87, 87-97

Genersch, E., von der Ohe, W., Kaatz, H., Schroeder, A., Otten, C., et al. (2010) The German bee monitoring project: a long term study to understand periodically high winter losses of honey bee colonies. Apidologie 41, 332-352

Giacobino, A., Bulacio Cagnolo, N., Merke, J., Orellano, E., Bertozzi, E., Masciangelo, G., Pietronave, H., Salto, C., Signorini, M. (2014) Risk factors associated with the presence of Varroa destructor in honey bee colonies from east-central Argentina. Prev. Vet. Med . doi:10.1016/j.prevetmed.2014.04.002

Giovanezzo, P., Dubreuil, P. (2011) Evaluation of spring organic treatments against Varroa destructor (Acari: Varroidae) in honey bee Apis mellifera (Hymenoptera: Apidae) colonies in eastern Canada. Exp. App. Acarol. 55, 65-76

Goodwin, R.M., Taylor, M.A., Mcbrydie, H.M., Cox, H.M. (2005) Base levels of resistance to common control compounds by a New Zealand population of Varroa destructor. New. Zeal. J. Crop. Hort. 33, 347-352

Guzmán-Novoa, E., Eccles, L., Calvete, Y., Mcgowan, J., Kelly, P.G., Correa Benitez, A. (2010) Varroa destructor is the main culprit for the death and reduced populations of overwintered honey bee (Apis mellifera ) colonies in Ontario, Canada. Apidologie 41, 443-450

Harris, J.W., Harbo, J.R., Villa, J.D., Danka, R.G. (2003) Variable Population Growth of Varroa destructor (Mesostigmata: Varroidae) in Colonies of Honey Bees (Hymenoptera: Apidae) during a 10-Year Period. Environ. Entomol. 32 (6), 1305-1312

Higes, M., Martín Hernández, R., Martínez Salvador, A., Garrido Ballón, E., González Porto, A.V., Meana, A., Bernal, J.L., del Nozal, M.J., Bernal, J. (2010) A preliminary study of the epidemiological factors related to honey bee colony loss in Spain. Environ. Microbiol. Rep. 2 (2), 243-250

Imdorf, A., Charriere, J.D., Kilchenmann, V., Bogdanov, S., Fluri, P. (2003) Alternative strategy in central Europe for the control of Varroa destructor in honey bee colonies. Apiacta 38, 258-285

Invernizzi, C., Harriet, J., Carvalho, S. (2006) Evaluation of different queen introduction methods in honeybee colonies in Uruguay. Apiacta 41, 1-20

Kulldorff, M. (2014) SaTScan User Guide for version 9.3. [Online] http://www.satscan.org (accessed on 05 May 14).

Kulldorff, M., Nagarwalla, N. (1995) Spatial Disease clusters: detection and inference. Statistics in Medicine 14, 799-810 
Le Conte, Y., Ellis, M., Ritter, W. (2010) Varroa mites and honey bee health: can Varroa explain part of the colony losses? Apidologie 41, 353-363

Lee, K.V., Moon, R.D., Burkness, E.C., Hutchison, W.D., Spivak, M. (2010) Practical sampling plans for Varroa destructor (Acari: Varroidae) in Apis mellifera (Hymenoptera: Apidae) colonies and apiaries. J. Econ. Entomol. 103 (4), 1039-1050

Liebig, G. (2001) How many Varroa mites can be tolerated by a honey bee colony? Apidologie 32 , 482-484

Lodesani, M., Colombo, M., Spreafico, M. (1995) Ineffectiveness of Apistan treatment against the mite Varroa jacobsoni Oud in several districts of Lombardy (Italy). Apidologie 26, 67-72

Lodesani, M., Costa, C., Man, M.C. (2006) Limits of chemotherapy in beekeeping: development of resistance and the problem of residues. Bulletin UASVM. Animal Science and Biotechnologies 62, [Online] http://journals.usamvcluj.ro/index.php/zootehnie/issue/view/93 (accessed on 01 May 14).

Maggi, M.D., Ruffinengo, S.R., Mendoza, Y., Ojeda, P., Ramallo, G., Floris, I., Eguaras, M.J. (2011) Susceptibility of Varroa destructor (Acari: Varroidae) to synthetic acaricides in Uruguay: Varroa mites' potential to develop acaricide resistance. Parasitol. Res. 108, 815821

Martin, S. (1998) A population model for the ectoparasitic mite Varroa jacobsoni in honey bee (Apis mellifera) colonies. Ecol. Model. 109, 267-281

Marcangeli, J.A., Eguaras, M.J., Fernández, N.A. (1992) Reproduction of Varroa jacobsoni (Acari: Mesostigmata: Varroidae) in temperate climates of Argentina. Apidologie 23 (1), 57-60

Mattila, H.R., Otis, G.W. (2006) Influence of pollen diet in spring on development of Honey Bee (Hymenoptera: Apidae) Colonies. J. Econom. Entomol. $99(3), 604$ 613

Milani, N. (1999) The resistance of Varroa jacobsoni Oud. to acaricides. Apidologie 30, 229-234

Moher, D., Hopewell, S., Schulz, K., Montori, V., Gøtzsche, P., Devereaux, P., Elbourne, D., Egger, M., Altman, D. (2010) ConSoRT 2010 explanation and elaboration: updated guidelines for reporting parallel group randomised trials. BMJ . doi:10.1136/bmj.c869

Moretto, G., Gonçalves, L.S., De Jong, D., Bichuette, M.Z. (1991) The effects of climate and bee race on Varroa jacobsoni Oud infestations in Brazil. Apidologie 22, 197-203

Oldroyd, B.P. (1999) Co-evolution while you wait: Varroa jacobsoni, a new parasite of western honeybees. Trends Ecol. Evol. 14(8), 312-315
Rosenkranz, P., Aumeier, P., Ziegelmann, B. (2010) Biology and control of Varroa destructor. J. Invertebr. Pathol. 103, 96-119

Schneider, S.S., De Grandi-Hoffman, G. (2008) Queen replacement in African and European honey bee colonies with and without afterswarms. Insectes Soc. 55, 79-85

Stevenson, M.A., Benard, H., Bolger, P., Morris, R.S. (2005) Spatial epidemiology of the Asian honey bee mite (Varroa destructor) in the North Island of New Zealand. Prev. Vet. Med. 71, 241-252

Strange, J., Sheppard, W.S. (2001) Optimum Timing of Miticide Applications for Control of Varroa destructor (Acari: Varroidae) in Apis mellifera (Hymenoptera: Apidae) in Washington State, USA. J. Econ. Entomol. 94 (6), 1324-1331

Tarpy, D.R., Hatch, S., Fletcher, D.J.C. (2000) The influence of queen age and quality during queen replacement in honeybee colonies. Anim. Behav. 59, 97-101

Tremolada, P., Bernardinelli, I., Colombo, M., Spreafico, M., Vighi, M. (2004) Coumaphos Distribution in the Hive Ecosystem: Case Study for Modeling Applications. Ecotoxicology 13, 589-601

Underwood, R.M., Currie, R.W. (2003) The effects of temperature and dose of formic acid on treatment efficacy against Varroa destructor (Acari:Varroidae), a parasite of Apis mellifera (Hymenoptera:Apidae). Exp. Appl. Acarol. 29, 303-313

van der Zee, R., Brodschneider, R., Brusbardis, V., Charrière, J.D., Chlebo, R., et al. (2014) Results of international standardised beekeeper surveys of colony losses for winter 2012-2013: analysis of winter loss rates and mixed effects modeling of risk factors for winter loss. J. Apic. Res. 53(1), 19-34

vanEngelsdorp, D., Evans, J.D., Saegerman, C., Mullin, C., Haubruge, E., et al. (2009) Colony Collapse Disorder: A descriptive study. PLoS ONE 4(8), e6481. doi:10.1371/journal.pone.0006481

vanEngelsdorp, D., Speybroeck, N., Evans, J.D., Nguyen, B.K., Mullin, C., et al. (2010) Weighing risk factors associated with bee colony collapse disorder by Classification and Regression Tree Analysis. J. Econ. Entomol. 103 (5), 1517-1523

Vetharaniam, I. (2012) Predicting reproduction rate of Varroa. Ecol. Model. 224, 11-17

Wilkinson, D., Smith, G.C. (2002) A model of the mite parasite, Varroa destructor, on honeybees (Apis mellifera) to investigate parameters important to mite population growth. Ecol. Model. $148,263-275$ 